\title{
Jogos Goianos da Saúde Mental: análise sobre o processo de participação
}

\author{
Heitor Martins Pasquim ${ }^{\circledR *}$, Gleyson Batista Rios $^{\mathrm{b}}{ }^{(}$, , Gabriela Cardoso Machado $^{\mathrm{a}}{ }^{\circledR}$, Francisco Luiz De Marchi ${ }^{\mathrm{a}}{ }^{\circledR}$
}

\author{
Palavras Chave: \\ Participação Social; \\ Saúde Mental; \\ Saúde Pública; \\ Jogos Recreativos.
}

Keywords:

Social Participation; Mental Health; Public Health; Recreational Games.

\begin{abstract}
RESUMO
Esta pesquisa busca entender o processo de participação na organização dos Jogos Goianos da Saúde Mental. A finalidade é contribuir com a reflexão sobre as possibilidades e limites de construção de redes de cuidado em saúde mental. Trata-se de pesquisa com análise documental, de abordagem descritiva e qualitativa, que seguiu procedimentos de análise de conteúdo. Identificaram-se duas categorias empíricas, a saber: da participação presencial à construção de rede; e decisões que impactaram a participação dos usuários. Advoga-se aqui uma participação profunda que mobiliza sonhos coletivos que as práticas manicomiais não conseguem colocar em uma camisa de força.
\end{abstract}

\begin{abstract}
This research project seeks to understand the process of participation in the organization of the Mental Health Games of Goiás. It aims to contribute to the reflection on the possibilities and limits of building mental health care networks. This is a documentary analysis research project, with descriptive and qualitative approach, which followed content analysis procedures. Two empirical categories were identified, namely: from face-to-face participation to network construction; and decisions that impacted the participation of users. A profound participation is advocated, which mobilizes collective dreams that asylum practices cannot put on a straitjacket.
\end{abstract}

\section{RESUMEN}

Esta investigación busca comprender el proceso de participación en la organización de los Juegos Goianos de Salud Mental. El objetivo es contribuir a la reflexión sobre las posibilidades y los límites de la construcción de redes de atención de salud mental. Se trata de una investigación con análisis documental, enfoque descriptivo y cualitativo, que siguió los procedimientos de análisis de contenido. Se identificaron dos categorías empíricas, a saber: desde la participación cara a cara hasta la construcción de redes; y decisiones que afectaron la participación de los usuarios. Aquí se aboga por una participación profunda que movilice sueños colectivos que las prácticas manicomiales no pueden poner en una camisa de fuerza.

\footnotetext{
a Universidade Federal de Goiás, Faculdade de Educação Física e Dança, Goiânia, GO, Brasil.

bUniversidade Estadual de Goiás, Escola Superior de Educação Física e Fisioterapia do Estado de Goiás, GO, Brasil.
}

\footnotetext{
* Autor correspondente: Heitor Pasquim

E-mail: hpasquim@gmail.com
}

Recebido em 14 de Novembro de 2019; Aceito em 18 de Dezembro de 2019. 


\section{INTRODUÇÃO}

Eventos artísticos, culturais e esportivos têm sido organizados pela Rede de Atenção Psicossocial RAPS, para proporcionar o encontro de trabalhadores, familiares e usuários da saúde mental, assim como a construção de redes sociais (Salles e Barros, 2013), articulando ações que compõem com estratégias de cuidado intersetoriais no território.

Em Goiânia, ocorreram vários eventos vinculados à saúde mental, que envolveram, em grande medida, elementos das práticas corporais como centralidade. Esses foram organizados pelo Fórum Goiano de Saúde Mental, por profissionais que trabalham em CAPS e pela Escola Superior de Educação Física e Fisioterapia do Estado de Goiás - ESEFFEGO.

Em 2018, inaugurou-se uma nova forma de organização desses eventos, a partir da primeira edição dos Jogos Goianos da Saúde Mental. Essa iniciativa acompanha outras em diferentes regiões do Brasil, como InterCAPS (Campinas - SP) e Copa da Inclusão (São Paulo - SP). Provavelmente, a Copa da Inclusão, realizada desde 2002, é o evento deste tipo com maior visibilidade no país.

Segundo Otsuka (2011) e Prefeitura de Goiânia (2018), as experiências paulistana e goiana promovem a participação dos usuários no planejamento e na realização dos eventos, portanto não mobilizam uma participação limitada à fruição de atividades, mas sim estimulam que o usuário assuma o papel principal na construção dos eventos, o que contribui para o sentimento de pertencimento, seja com o grupo ou com o projeto coletivo.

Ressalta-se que o conceito de participação é polissêmico e remete tanto à mudança como à coesão social (Stotz, 2019), em que grupos compartilham objetivos, crenças, ideias e ações, fortalecendo um espaço inclusivo. Nesse sentido, a participação é de suma importância, pois na saúde mental, "o que se pretende é uma rede de relações entre sujeitos, sujeitos que escutam e cuidam [...] com sujeitos que vivenciam as problemáticas" (Amarante, 2007, p. 82).

Na medida em que essa participação mobiliza o sujeito e grupos sociais do ponto de vista emocional e racional, ela pode ser entendida como necessidade social de saúde (Campos, Bataiero, 2007), que aumenta a consciência sobre o processo saúde doença (Paim, 2006), e por isso pode se constituir como ferramenta de transformação da realidade do dito "louco". Todavia, Costa e Paulon (2012) apontam que nem sempre esses espaços de participação resultam em experiências de incremento à capacidade das pessoas de interferirem nos rumos da própria vida. Nesse sentido, é necessário questionar qual participação a saúde mental tem construído.
Com isso, esta pesquisa busca entender como os Jogos Goianos da Saúde Mental privilegiam a participação. A finalidade desta pesquisa é contribuir com a reflexão sobre as possibilidades e limites de construção de redes de cuidado em saúde mental.

\section{MÉTODO}

Trata-se de pesquisa com análise documental, de abordagem descritiva e qualitativa (Gil, 2018), que seguiu procedimentos de análise de conteúdo, na modalidade temática (Minayo, 2012).

Essa técnica de análise procede por aproximações sucessivas de interpretação para descobrir os núcleos de sentido. As a proximações se constituem em atividade de elaboração mediada pela reflexão que permite tomar consciência sobre o conteúdo. Compreendem-se os conteúdos como mediação da realidade, e, nesse caso, expressam interesses e intencionalidades dos sujeitos.

Para analisar o objeto de interesse (participação) foram elencadas categorias a posteriori, ou seja, a partir da leitura das fontes primárias, sendo que para garantir o rigor científico do processo de categorização empírica dos dados, realizaram-se leituras exaustivas dos documentos.

Cinco fontes primárias foram investigadas, a saber: atas das cinco reuniões gerais de organização dos Jogos Goianos da Saúde Mental, 2018. Nas atas analisadas há relatos de outras reuniões de comissões específicas, porém o registro delas não está disponível.

As atas foram disponibilizadas publicamente pela comissão organizadora dos Jogos. Elas estão disponíveis nos serviços de saúde mental de Goiânia e em rede social (Pasquim, 2018). Dessa forma, não se aplica pedido de comissão de ética.

Para facilitar a identificação das fontes na apresentação dos resultados, elas receberam códigos, conforme Quadro 1.

Quadro 1. Identificação dos documentos selecionados.

\begin{tabular}{|ll|}
\hline Identificação & \multicolumn{1}{c|}{ Documento } \\
\hline A1 & Ata da 1a Reunião Geral \\
A2 & Ata da 2ạ Reunião Geral \\
A3 & Ata da 3a Reunião Geral \\
A4 & Ata da 4a Reunião Geral \\
A5 & Ata da 5ạ Reunião Geral \\
\hline
\end{tabular}

Fonte: elaboração própria, 2019.

\section{RESULTADOS}

Embora as atas das reuniões gerais não possuam uma forma rígida, todas elas trazem informações sobre a quantidade de participantes, pautas, discussões resumidas e deliberações. 
Para facilitar a leitura do material, os resultados estão apresentados em ordem cronológica.

A ideia de um encontro cultural, artístico e esportivo, realizado pela saúde mental goiana, foi descrita como estratégia com grande potencial para rearticular os serviços e fortalecer o sistema de saúde.

Os participantes desta primeira reunião analisaram juntos outras experiências de construção de eventos semelhantes, em especial a Copa da Inclusão, e, a partir disso, pontuaram dúvidas em relação à competição e à premiação; inscrição de atletas, artistas e expositores; a necessidade de facilitar o acesso aos familiares; a preocupação com riscos à saúde; dificuldade para viabilizar a alimentação, o transporte e a mobilização dos serviços.

Algumas propostas iniciais foram surgindo do debate coletivo, como: regra para votação na reunião geral; produção de estandarte e de flâmula por serviço; homenagem à ativista goiana da luta antimanicomial "Deusdete"; estratégias para mapear preferências e habilidades dos usuários da RAPS. Esses debates resultaram em deliberações.

As principais deliberações dessa reunião foram: data dos Jogos (01/12/2018); local dos Jogos (FEFD/ UFG); orientação geral para a premiação (privilegiar a participação); homenagem à Deusdete; exigência de pelo menos um usuário para que o serviço possa votar em reuniões gerais; constituição e indicação de membros de uma Comissão Geral Provisória com profissionais de saúde (Cuca Fresca e Consultório na Rua) e universidade (FEFD); e data da segunda reunião de organização dos Jogos (27/09).
Algumas pessoas apontaram, nesta segunda reunião, as modalidades mais praticadas ou lembradas pelos usuários da RAPS. Relataram também a dificuldade em conseguir atestado médico, confirmando a dificuldade de articulaçãoda rede. Odebate fezsurgiralgumas discussões, como o direito do usuário ao cuidado integral que não acontece apenas no CAPS, assim como a possibilidade de se ter uma orientação da gerência estadual para facilitar essa articulação local. Citou-se ainda, como sugestão, reduzir a intensidade de esforço, escolhendo modalidades que não privilegiem o aumento do débito cardíaco e que permitam intervalos para descanso.

Nesta reunião, criou-se o Termo de Responsabilidade que deveria ser assinado pelo gestor local. A partir dele, o serviço se responsabiliza em escolher quais usuários estão em condições de saúde para a prática esportiva, e portanto, podendo participar do evento.

Outras questões preocupavam o grupo para a operacionalização do evento, entre elas: a divulgação, a alimentação, o transporte e a dificuldade de os trabalhadores comparecerem no sábado - dia escolhido para a realização dos Jogos.

As deliberações desta reunião foram: criação de evento em rede social, onde seriam socializadas fotos, atas, entre outras informações relevantes; construção de Termo de Responsabilidade; Formulário Online para inscrição; ratificação da Comissão Geral (com a mesma composição da comissão provisória) e indicação de membros das Comissões de Esporte (usuário, profissionais da saúde e estagiários da FEFD), Arte/ Cultura/ Economia Solidária

Quadro 2. Ata da 1a Reunião Geral.

\begin{tabular}{|lcc|}
\hline Data & \multicolumn{1}{c|}{ Local } & Participantes \\
\hline 13/09/2018 & Centro de Convivência e Cultura Cuca Fresca & 25 pessoas \\
& Serviços e representantes presentes \\
CCC Cuca Fresca (Goiânia); CAPS Casa (Goiânia); CAPS AD Ipê (Goiânia); CAPS Novo Mundo (Goiânia); Gerarte I (Goiânia); \\
$\begin{array}{l}\text { Gerarte II (Goiânia); Consultório na Rua (Goiânia); Gerência de Saúde Mental da Superintendência de Políticas de Atenção } \\
\text { Integral à Saúde do Estado de Goiás; FEFD/UFG. }\end{array}$
\end{tabular}

Fonte: elaboração própria, 2019.

Quadro 3. Ata da 2a Reunião Geral.

\begin{tabular}{|lr|}
\hline Data & Local \\
\hline 27/09/2018 & Centro de Convivência e Cultura Cuca Fresca \\
& Serviços e representantes presentes
\end{tabular}

Fonte: elaboração própria, 2019. 
(profissionais da saúde), Infraestrutura (profissionais da saúde, docentes e estagiários da FEFD) e Divulgação (profissionais da saúde e docente da FEFD); e data da reunião seguinte (11/10).

Os repasses da Comissão de Esporte e da Comissão de Arte/ Cultura/ Economia Solidária pautaram a terceira reunião.

A Comissão de Esporte apresentou questões discutidas internamente. A partir disso, os presentes definiram as modalidades que pontuariam para a premiação nos Jogos: Dama; Dominó; Queimada Mista; Jogo da Memória; Tênis de Mesa; Basquete Street; Vôlei Misto; Torneio de Golzinho. Consideraram ainda que a pontuação deveria favorecer a participação e não a competição. Issoé, o serviço ganha ponto por participação e não por vitória, mas a participação em modalidades que exijam articulação de rede (por exemplo, atestado médico) valeriam mais pontos, do que modalidades que não exigem essa articulação/ mobilização.

Ficou definido também que 0 atestado médico seria obrigatório para a participação nas modalidades de basquete, golzinho e atletismo. Outras práticas comporiam a programação na forma de oficinas e vivências (sem pontuação), como Slackline, Basquete de Arremesso, Futebol para Cegos, Jogos Cooperativos, Jogos com Baralho e Peteca.

Os participantes desta reunião rejeitaram proposta de subcategorias por idade, apresentada pela Comissão de Esporte. Nessa reunião o grupo participante preferiu organizar apenas duas categorias: adultos e crianças.

Em seguida, a Comissão de Arte/Cultura/ Economia Solidária relatou pontos específicos debatidos por eles. A comissão advoga que todos os participantes deveriam ganhar medalhas, mesmo aqueles que participassem apenas da economia solidária ou de apresentações culturais, e que os usuários deveriam ser estimulados a propor oficinas durante os Jogos.

Ficou decidido quais seriam as modalidades de apresentação: Música; Dança; Teatro; Poesia; Batalha de Rap; e Exposição de Arte. Assim como os princípios que norteariam a Feira de Economia Solidária, a saber: autogestão; democracia; solidariedade; cooperação; respeito à natureza; comércio justo; e consumo solidário.

Em outra decisão, o grupo estabelece que o serviço que acumular mais pontos coletivamente leva o troféu Deusdete. Esse troféu é itinerante, ou seja, ele fica apenas um ano na unidade vitoriosa. Depois disso ele retornaria para uma nova disputa.

Para encerrar a reunião, uma representante do Fórum Goiano da Saúde Mental - FGSM foi convidada a contar um pouco da história da ativista homenageada. Segundo relato, Deusdete do Carmo Martins fez da luta sua vida, foi psicóloga, especialista em Saúde Pública, precursora do Movimento da Luta Antimanicomial em Goiás na década de 1980 e participou da criação do Fórum Goiano da Saúde Mental.

Duas pautas importantes foram debatidas nesta quarta reunião. A primeira foi a escolha da arte e a segunda o Regulamento dos Jogos Goianos da Saúde Mental.

Antes desta reunião, a Comissão Geral e a Comissão de Divulgação entraram em contato com diversos serviços pedindo que os profissionais da saúde mental propusessem aos participantes dos grupos terapêuticos desenhar propostas de arte para os Jogos. Foram recebidas 9 propostas de arte.

Cada arte foi apresentada e recebeu votos. Seguiuse a regra que exige a presença de usuários para que o serviço possa votar, o que explica a diferença entre a quantidade de pessoas presentes na reunião e a quantidade de votos.

Por maioria simples de votos, a Arte 9 foi a escolhida. Essa arte foi feita por um usuário do CCC Cuca Fresca.

Em seguida à escolha da arte, iniciou-se a discussão do Regulamento dos Jogos Goianos da Saúde Mental - 2018. A discussão foi pautada por proposta inicial da Comissão Geral, que, por sua vez, tomou como referência o regulamento da Copa da Inclusão de 2017.

Foram feitos diversos destaques que geraram discussões e novas sínteses. $O$ texto recebeu ao todo 21 destaques. Discutiram-se, por exemplo, inscrição e

Quadro 4. Ata da 3a Reunião Geral.

\begin{tabular}{|c|c|c|}
\hline Data & Local & Participantes \\
\hline $11 / 10 / 2018$ & Centro de Convivência e Cultura Cuca Fresca & 26 pessoas \\
\hline \multicolumn{3}{|c|}{ Serviços e representantes presentes } \\
\hline \multicolumn{3}{|c|}{$\begin{array}{l}\text { CAPS Vidativa (Anápolis); CAPS Reencontro (Senador Canedo); CAPS AD Vila Santa Rosa (Senador Canedo); CAPS AD Viver } \\
\text { (Anápolis); CAPS AD III Criarte Vida (Aparecida de Goiânia); CCC Cuca Fresca (Goiânia); CAPS AD Casa (Goiânia); CAPS Beija } \\
\text { Flor (Goiânia); CAPS Girassol (Goiânia); CAPS AD Ipê (Goiânia); CAPS Novo Mundo (Goiânia); CAPS Noroeste (Goiânia); Gerarte } \\
\text { I (Goiânia); Gerarte II (Goiânia); Bloco Desencuca; Fórum Goiano da Saúde Mental - FGSM; Gerência de Saúde Mental da } \\
\text { Superintendência de Políticas de Atenção Integral à Saúde do Estado de Goiás; FEFD/UFG. }\end{array}$} \\
\hline
\end{tabular}

Fonte: elaboração própria, 2019. 
Quadro 5. Ata da 4a Reunião Geral.

\begin{tabular}{|c|c|c|}
\hline Data & Local & Participantes \\
\hline $23 / 10 / 2018$ & Centro de Convivência e Cultura Cuca Fresca & 33 pessoas \\
\hline \multicolumn{3}{|c|}{ Serviços e representantes presentes } \\
\hline \multicolumn{3}{|c|}{$\begin{array}{l}\text { CAPS AD Viver (Anápolis); CAPS AD III Criarte Vida (Aparecida de Goiânia); CCC Cuca Fresca (Goiânia); CAPS Beija Flor (Goiânia); } \\
\text { CAPS AD Ipê (Goiânia); CAPS Noroeste (Goiânia); Gerarte II (Goiânia); Bloco Desencuca; Consultório na Rua (Goiânia); } \\
\text { Consultório na Rua (Aparecida de Goiânia); Gerência de Saúde Mental da Superintendência de Políticas de Atenção Integral } \\
\text { à Saúde do Estado de Goiás; FEFD/UFG. }\end{array}$} \\
\hline
\end{tabular}

Fonte: elaboração própria, 2019.

Quadro 6. Quantidade de votos por arte. Jogos Goianos da Saúde Mental, 2018.

\begin{tabular}{|lcccccccccc|}
\hline & Arte $\mathbf{1}$ & Arte $\mathbf{2}$ & Arte $\mathbf{3}$ & Arte $\mathbf{4}$ & Arte $\mathbf{5}$ & Arte $\mathbf{6}$ & Arte $\mathbf{7}$ & Arte $\mathbf{8}$ & Arte $\mathbf{9}$ & Total \\
\hline Votos & 04 & 06 & 03 & 01 & 0 & 0 & 0 & 01 & 11 & 26 \\
\hline
\end{tabular}

Fonte: elaboração própria, 2019.

horário das cerimônias de abertura e encerramento. Outros pontos foram rediscutidos, como a pontuação das modalidades de esporte que foi adaptada para valorizar mais os esportes coletivos do que os esportes individuais e a exposição na Feira de Economia Solidária que ficou restrita apenas a usuários da saúde mental.

Essa reunião não finalizou a aprovação do Regulamento, deixando essa tarefa para a reunião seguinte, agendada para o dia 08/11.

Os informes iniciais da quinta reunião apontam preocupações com uma possível ênfase na competição, por conta da utilização de tabelas e de chaveamento nos esportes coletivos, e a falta de apoio da gestão para obter transporte, mas também aponta o entusiasmo dos usuários e dos trabalhadores com a aproximação dos Jogos.

Relatam-se a desinformação e dificuldades no processo de inscrição, principalmente no caso de serviços que não conseguem participar de forma presencial nas reuniões organizativas.

Nesta reunião surgem ideias novas, como a confecção artesanal de camisetas no dia do evento e o critério de desempate para a premiação (torcida mais animada). Foi debatida ainda a necessidade de a abertura ser conduzida por falas curtas, garantindo voz para usuário e autoridades, exclusivamente ligadas à saúde e à universidade.

Propôs-se também que o ritual de abertura deveria envolver um desfile de delegações por unidade de saúde na pista de atletismo da FEFD e que cada serviço deveria confeccionar um cartaz com o nome da unidade para usar no desfile. Após o desfile esses cartazes seriam costurados em uma grande colcha para ser apresentada a todos na cerimônia de encerramento. A ideia é apresentar a grande colcha como uma simbologia da articulação e força da RAPS.

A Comissão de Infraestrutura relatou discussões internas. Informa que será feita uma galinhada (paga por doações) no CAPS Noroeste para distribuir durante os Jogos. Relatam também outros pontos importantes, mas sem encaminhamentos, como o espaço para plenárias de autogestão de usuários e de trabalhadores durante o evento.

A Comissão de Divulgação apresentou e distribuiu o cartaz diagramado, a partir da arte escolhida. A diagramação foi feita pela Secretaria de Comunicação da UFG (Figura 1).

Finalmente, o regulamento, com alterações, foi aprovado. As principais alterações dizem respeito a melhor descrição de regras de cada modalidade; a

Quadro 7. Ata da 5a Reunião Geral.

\begin{tabular}{|c|c|c|}
\hline Data & Local & Participantes \\
\hline $08 / 11 / 2018$ & Centro de Convivência e Cultura Cuca Fresca & 21 pessoas \\
\hline \multicolumn{3}{|c|}{ Serviços e representantes presentes } \\
\hline \multicolumn{3}{|c|}{$\begin{array}{l}\text { CAPS AD III Infanto-Juvenil (Aparecida de Goiânia); Consultório na Rua (Aparecida de Goiânia); CAPS infantil Crescer (Anápolis); } \\
\text { CAPS AD Viver (Anápolis); CAPS AD III Criarte Vida (Aparecida de Goiânia); CCC Cuca Fresca (Goiânia); CAPS Girassol (Goiânia); } \\
\text { CAPS AD Ipê (Goiânia); Hospital Casa de Eurípedes (Goiânia); Gerarte I (Goiânia); Consultório na Rua (Goiânia); Pronto- } \\
\text { Socorro Psiquiátrico Wassily Chuc (Goiânia); Fórum Goiano da Saúde Mental; Gerência de Saúde Mental da Superintendência } \\
\text { de Políticas de Atenção Integral à Saúde do Estado de Goiás; FEFD/UFG. }\end{array}$} \\
\hline
\end{tabular}

Fonte: elaboração própria, 2019. 


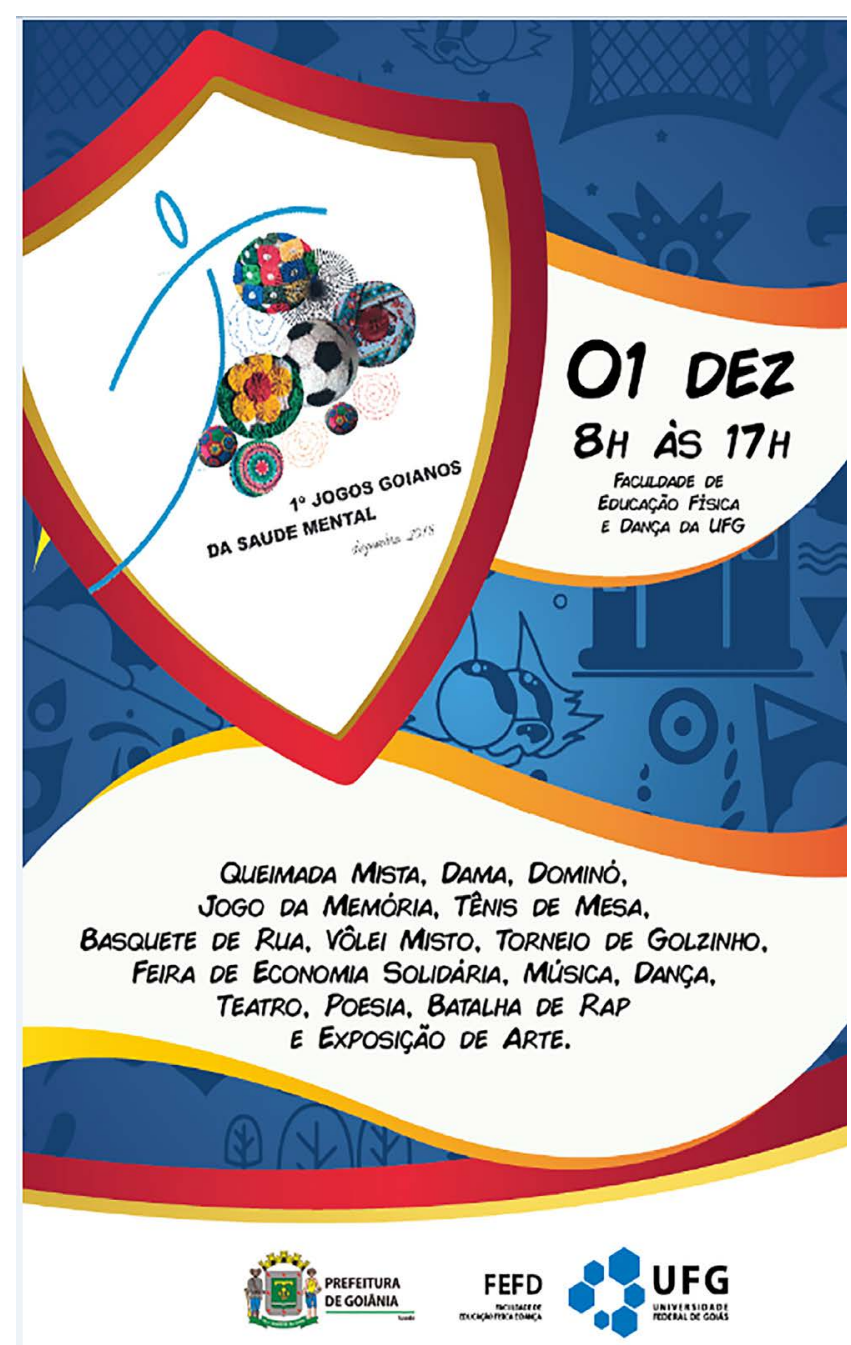

Figura 1. Cartaz dos Jogos Goianos da Saúde Mental. Fonte: FEFD (2019).

garantia de participação de todos (inclusive usuários inscritos como reservas nos times); e decisão sobre permanência de troféu no serviço campeão, ou seja, a decisão do troféu itinerante foi abortada.

\section{DISCUSSÃO}

As atas relatam o processo de organização da primeira edição dos Jogos Goianos da Saúde Mental, realizada em 2018. Ressalta-se que os documentos analisados não são independentes, mas que existe uma manifestação discursiva que lhes dá unidade. Todavia, o processo de organização não aconteceu de forma linear, senão em um movimento dialógico que mobilizou o inédito-viável, conforme termo descrito por Freire (2016).

A participação nas reuniões gerais dos Jogos Goianos da Saúde Mental objetivava transformar ideias em ação, mas ela não tinha uma forma $a$ priori. Portanto, ela se realizou no processo, nesse caso, mediada pela organização de um evento esportivo, artístico e cultural.
Na verdade, essa participação democrática enriquece o processo, porque cria corresponsabilidade com a efetivação do plano de ação, dando legitimidade e viabilidade ao projeto.

Um processo participativo é necessariamente influenciado pelos dispositivos organizadores da presença, ou seja, as formas de agenciamento coletivo. No caso observado, esse dispositivo foi a reunião geral.Não há uma hierarquização preestabelecida na reunião, o que pode indicar tanto uma construção já horizontalizada das relações, como um exercício por parte dos envolvidos, principalmente dos trabalhadores, em não hierarquizar os processos de decisão, tampouco há garantias de que o que se discute ali será materializado em ação. De fato, algumas ideias registradas em atas aparecem e desaparecem sem se concretizar. Por exemplo, a produção de flâmulas, que deveriam ser trocadas antes de cada partida (A1). Essa ideia não é retomada em nenhuma outra reunião. De tal forma, que a força não está depositada na participação com fim em si mesma, mas nas ações que elas mobilizam. Ou seja, naquilo que pode vir a ser.

A partir da leitura exaustiva dessas fontes primárias, identificaram-se duas categorias empíricas: da participação presencial à construção de rede; e decisões que impactaram a participação dos usuários.

\section{Da participação presencial à construção de rede}

Algumas questões influenciaram diretamente a presença na reunião geral. Por exemplo, a sede. Nesse caso, todas as reuniões de organização aconteceram no Centro de Cultura e Convivência "Cuca Fresca", no Jardim América, em Goiânia/GO. Por um lado, a sede única pode ter dificultado uma participação presencial mais ampla, do que uma sede em rodízio. Por outro, o Cuca Fresca é um dispositivo bastante simbólico para a unidade da luta antimanicomial goiana e, por isso, pode ter facilitado a mobilização dos demais serviços. Ademais, os objetivos dos Centros de Cultura e Convivência (Lei no 10.216/2001) convergem com a construção coletiva de espaços de coexistência e fortalecimento de vínculos solidários, por meio de práticas que promovam cultura, saúde e lazer.

Em 2016, o Cuca Fresca foi fechado, reabrindo no ano seguinte, após intensas lutas sociais e ação judicial proposta pela Defensoria Pública do Estado de Goiás (O Popular, 2017), o que evidencia o simbolismo da resistência que esse serviço carrega contra políticas autoritárias em Goiás.

Observando a data da primeira reunião (13/09/2018) e a realização dos Jogos (01/12/2018) é possível concluir que o processo de participação ocorreu em um intervalo de apenas três meses, tempo 
curto para organização de um evento estadual, o que pode ter influenciado negativamente na promoção de mais participação.

A participação pode ser quantificada pela presença de diferentes cidades nas reuniões. Destaca-se que os Jogos Goianos anunciam uma organização estadual, porém das 246 cidades goianas apenas 5 participaram das reuniões de organização: Goiânia; Anápolis; Goianira; Senador Canedo; e Aparecida de Goiânia. Excetuando Anápolis, todas as outras cidades compõem a chamada Região Metropolitana de Goiânia - RMG.

No entanto, a quantidade de dispositivos participantes não é insignificante. Dos 71 Centros de Atenção Psicossocial do Estado de Goiás (CNES, 2019), 14 (19,7\%) participaram presencialmente de pelo menos uma reunião de organização. Segundo A5, outros serviços participariam apenas no dia do evento.

Sabe-se que a presença é uma representação assimétrica e que algumas instituições se fizeram presentes em todas as reuniões. É o caso do Cuca Fresca e da FEFD. Todavia, foram os CAPS que mobilizaram mais pessoas. Outras organizações dos usuários estiveram presentes, como a Associação dos Usuários dos Serviços de Saúde Mental - AUSSM, o Bloco Desencuca, o Fórum Goiano da Saúde Mental - FGSM e serviços ligados à economia solidária (Gerarte I e II).

Chama atenção, em A5, a participação do ProntoSocorro Psiquiátrico "Wassily Chuc" e do Hospital Casa de Eurípedes. Embora a organização dos serviços em rede seja um princípio do SUS, a reforma psiquiátrica brasileira anuncia a construção de uma rede substitutiva aos dispositivos tradicionais (representados pelos antigos manicômios e hospitais psiquiátricos). Neste sentido, a RAPS seria composta por serviços como Centros de Atenção Psicossocial, Residências Terapêuticas e Centros de Convivência e Cultura (Lei no 10.216/2001) entre outros, excetuando-se hospitais psiquiátricos e manicômios. Contraditoriamente, os serviços tradicionais e substitutivos constroem rede na prática.

A participação em reuniões gerais dos Jogos instaurou um espaço de aparição de grupos invisíveis. Por exemplo, proposta de fala de usuários na abertura do evento na Faculdade de Educação Física e Dança FEFD (A5), ou seja, o que está em disputa não é apenas a construção dos Jogos, mas a criação do encontro, do contato e da ocupação de espaço público.

A presença não é voluntarismo, ela é política (Dallari, 2017). Na atualidade, determinações sociais barram a disponibilidade e colocam a todos em um regime de semipresença constante (Comitê Invisível, 2016), mediada por uma aparelhagem sofisticada da ausência. Em uma sociedade adoecida, soma-se à crise econômica, ecológica e política, uma crise de presença.
Essa crise de presença é superada em parte. Os Jogos de 2018 oportunizaram diferentes formas de ocupação da universidade, possibilitando a interação com a comunidade acadêmica também.

A colcha de retalhos (A5) celebra o fortalecimento da rede, identificada como falha logo nas primeiras reuniões (A2). De fato, a construção permanente de rede faz-se necessária. Em geral, sistemas fragmentados vinculam-se a modelos de atenção que respondem às condições agudas, enquanto sistemas integrados estão articulados a modelos de atenção às condições crônicas (Mendes, 2018).

\section{Decisões que impactaram a participação dos usuários}

A participação ampla de usuários da RAPS na organização dos Jogos foi defendida desde a primeira reunião. Essa defesa se materializou em ações concretas, como na ideia que pretendia identificar preferências e habilidades dos frequentadores dos CAPS (A1); na regra que exige a presença de usuários para que o serviço pudesse votar (A1); na escolha da arte produzida por um usuário (A4); no estímulo para que os usuários pudessem propor oficinas durante os Jogos (A3); e na garantia de fala de usuários na abertura (A5).

A competição e a participação não-competitiva aparecem nas atas como discursos em oposição, sendo que a participação não-competitiva é mais valorizada como meio para aumentar a participação dos usuários (A1, A3, A4 e A5).

Contraditoriamente, foi possível identificar que apenas a Comissão de Esporte agregou formalmente usuário da RAPS. Todas as outras comissões foram compostas por trabalhadores da saúde mental, gestores municipais e/ou estaduais, estudantes e docentes da Faculdade de Educação Física e Dança - FEFD.

No mesmo sentido, o grupo participante das reuniões, preocupado com a saúde e segurança, delibera que quem deve escolher quais usuários estão em condições para a participação no evento é o serviço, em último caso o gestor local (A2), o que demonstra que o protagonismo dos usuários não é algo natural ou dado. Mesmo com contradições, a participação dos usuários é uma meta constante nas 5 reuniões gerais.

Para Paim (2006), a identificação dos problemas e dos meios de superá-los eleva a consciência das pessoas, facilitando a mobilização política dos interessados. Esse processo é educativo porque produz novas sínteses para a superação de barreiras comuns e porque fortalece o coletivo envolvido, elevando a consciência sobre a totalidade.

As questões que emergiram durante a construção dos Jogos 2018 expressaram problemáticas da rede 
de saúde pública de Goiás, como a "falta de médicos". Mas não é possível identificar se isso gerou tensão que pudesse modificar a realidade.

Advoga-se aqui que a participação não depende apenas de esforços individuais, nem exclusiva e nem majoritariamente, e só podem florescer em formas livres de organização antimanicomiais, que permitam discussões sobre o processo de trabalho e de vida para a construção de práticas emancipatórias que promovam uma participação profunda.

É possível afirmar que a organização dos Jogos Goianos da Saúde Mental é uma experiência de autogestão. Nesse sentido, a ideia de participação profunda difere de uma participação simplesmente ativa, um "fazer coisas". Afinal, esse mecanismo de ocupação anula a política, impede a fala autônoma e transgressora.

Vale ressaltar como limitação deste estudo que as atas não são documentos com rigor acadêmico. Entretanto, elas representam a interpretação e a síntese do grupo participante. A pesquisa centrada nos documentos produzidos em reunião não permite uma investigação mais específica do amadurecimento dessa participação. Sabe-se, porém, que uma maior participação possui evidentes limitações estruturais, sociais e culturais. As limitações têm como pano de fundo uma conjuntura adversa aos grupos populacionais historicamente marginalizados. Estudos complementares são necessários para o desenvolvimento de estratégias que facilitem o amadurecimento da participação dos usuários da saúde mental.

\section{CONCLUSÃO}

Este estudo descreve um processo de participação cheio de contradições e dificuldades e, por isso, rico. Sem dúvida, a organização dos Jogos Goianos da Saúde Mental - 2018 foi um objetivo ousado e complexo que exigiu muito planejamento.

Além disso, é possível afirmar que a opção em fazer um planejamento participativo envolveu os sujeitos da saúde mental (usuários, familiares e trabalhadores) na identificação das suas necessidades, processo educativo e emancipador.

Assim como no lema adotado pela luta das pessoas com deficiência - "nada sobre nós, sem nós", a construção da mudança na saúde mental deve contemplar a plena e efetiva participação dos sujeitos concretamente envolvidos.

Nessa perspectiva, o processo observado no estudo propiciou a construção de rede e impactou a participação dos usuários da RAPS. A reflexão sobre a democratização do processo, com ênfase em relações horizontalizadas, é potente para gerar mudanças radicais, que ainda precisarão ser investigadas por novas pesquisas.
Advoga-se aqui uma participação profunda que mobiliza sonhos coletivos que as práticas manicomiais contemporâneas não conseguem colocar em uma camisa de força.

Espera-se, assim, que o evento Jogos Goianos da Saúde Mental, gestado pelos sujeitos da saúde mental goiana, possa seguir dando frutos e estimular a produção de políticas e práticas antimanicomiais.

\section{REFERÊNCIAS}

Amarante P. Saúde Mental e Atenção Psicossocial. Rio de Janeiro: Fiocruz; 2007.

Campos CMS, Bataiero MO. Necessidades de saúde: uma análise da produção científica brasileira de 1990 a 2004. Interface (Botucatu). 2007;11(23):605-18.

Comitê Invisível. Aos nossos amigos: crise e insurreição. São Paulo: N-1 edições; 2016.

Costa DFC, Paulon SM. Participação Social e protagonismo em saúde mental: a insurgência de um coletivo. Saúde debate. 2012;36(95):572-82.

CNES. Consulta estabelecimento. Disponível em: 05 de Julho de 2019. No endereço eletrônico: http://cnes.datasus.gov.br/ pages/estabelecimentos/consulta.jsp

Dallari DA. O que é participação política. Primeiros Passos. 1a ed. Ebook. São Paulo: Brasiliense; 2017.

FEFD. I Jogos Goianos da Saúde Mental - Participe! Disponível em: 25 de junho de 2019. No endereço eletrônico: https://www. fefd.ufg.br/e/22223-i-jogos-goianos-da-saude-mental-participe

Freire P. Pedagogia do Oprimido. 17a ed. Rio de Janeiro: Paz e Terra; 2016.

Gil AC. Como elaborar projetos de pesquisa. 6a ed. São Paulo: Atlas; 2018.

Mendes EV. O cuidado das condições crônicas na atenção primária à saúde. Rev Bras Promoção da Saúde. 2018;31(2):1-3.

Minayo MCS. O desafio do conhecimento: pesquisa qualitativa em saúde. 14a ed. São Paulo: Hucitec; 2012.

OPopular. Justiça bloqueia R\$ 129 mil da conta da Secretaria Municipal de Saúde de Goiânia. Publicado em 24/11/2017. Disponível em: 18/06/2019. No endereço eletrônico: https://www.opopular.com.br/noticias/cidades/ justi\%C3\%A7a-bloqueia-r-129-mil-da-conta-da-secretariamunicipal-de-sa\%C3\%BAde-de-goi\%C3\%A2nia-1.1402103

Otsuka E. Saúde Mental, Lazer e Cotidiano na Copa da Inclusão. São Paulo: Biblioteca24horas; 2011.

Paim JS. The "1967 National Health Plan" and today's "prepaid health plans": anything in common? Rev. Saúde Pública. 2006;40(3):386-8.

Pasquim H. I Jogos Goianos da Saúde Mental - 2018. Disponível em: 25 de junho de 2019. No endereço eletrônico: https:// www.facebook.com/events/535371370235098/

Prefeitura deGoiânia.JogosGoianosdaSaúdeMentalserãorealizados neste sábado, $1^{\circ}$. Disponível em: 25 de junho de 2019. No endereço eletrônico:http://www4.goiania.go.gov.br/portal/ pagina/?pagina=noticias $\& s=1 \& t t=$ ot $\& c d=16225 \& \mathrm{fn}=$ true

Salles MM, Barros S. Inclusão social de pessoas com transtornos mentais: a construção de redes sociais na vida cotidiana. Ciência \& Saúde Coletiva. 2013;18(7):2129-38.

Stotz EN. Participação Social (verbete). Disponível em: 19/06/2019. No endereço eletrônico: http://www.sites.epsjv.fiocruz.br/ dicionario/verbetes/parsoc.html 